\title{
Comparison of flow and erosion sedimentation measurement with [HEC-2] and [HEC-6] computer models for Koohsefid River
}

\author{
M. Najarchi \\ Department of Irrigation Science, Faculty of Agriculture, \\ Islamic Azad University, Arak Branch, Iran
}

\begin{abstract}
Koohsefid River is located in the southwest of Mahalat City in the Markazi Province of Iran. [HEC-2] and [HEC-6] computer models were used for the investigation of flood events, water surface profiles and erosion sedimentation with different return periods for Koosefid River respectively. Based on the results obtained from [HEC-2] a high correlation is shown with data observing by floodmark. Erosion and sedimentation in the river with [HEC-6] model uses different formulas for such prediction. To verify the accuracy of these formulas, measurement of sediment in hydrometry station was also performed. Toffaleti's formula using fall velocity introduced by the Interagency Committee on Water Resources (I.C.W.R) approach shows the highest correlations with measured values.
\end{abstract}

Keywords: HEC-2, HEC-6, sedimentation, river.

\section{Introduction}

One of the most important principles for the development and growth of a country is the demand for water, for use in agriculture, supplies for drinking and industrial consumption. The main source of this vital element is river water, rivers transport material and sediments at a rate of millions of tons every year. In designing and building temporary diversions and their levels of performance it is important to recognize the quality and quantity of transport material in the stream flow. Studying a history of cases shows that conveyance channels and capacitance dams are destroyed that by the transition caused by the accumulation 
of sediments from farms, where agriculture fields are changed to barren regions, therefore, stream-bank erosion control is important in operations and engineering designs of a river. Moien tahgave provided [HEC-6] and [HEC-2] computer models for the prediction of a water surface profile and dam store sediment and attribute satisfactory results [1]. Najarchi used [HEC-6] model that determined sediment in irrigation and drainage of the Voshmgir Dam and accounted values attributed to a model and compared it with measured values and results obtained to show that the model is suitable for determination of sediments in concrete channels [2]. Monem applied [HEC-6] model for an alluvial channel. He concludes that values of sedimentation and erosion have a high correlation with measured values. We can use this model for one-dimensional flow conditions [3].

\section{Materials and methods}

Koohsefid River is located southwest of Mahalat in the Markazi province of Iran. This river transfers all of the surface runoff to the outside of the watershed. We focused on the 2.5 kilometers of river in this research. We used [HEC-2] computer modeling in this part of the river to investigate flood events and water surface profiles, furthermore we used [HEC-6] computer model to predict values of transport sediment and erosion in the river. This model simulates the capability of a stream to transport sediment. This computation of transport includes both bed and suspended load as described by Einstein's bed load function [4].

\section{1 [HEC-2] computer model}

The model is intended for calculation of water surface profiles for steady, gradually varied flow in natural or man-made channels. Both subcritical and supercritical flow profiles can be calculated. The effects of various obstructions such as bridges, culverts, weirs, and other structures in the floodplain may be considered in the computations. The computation procedure is based on the solution of the one-dimensional energy equation with energy loss due to friction evaluated with Manning's equation. The model is also designed for application in floodplain management and flood insurance studies to evaluate floodway encroachments [5]. Water surface profile for flood event with return period of 25 years was calculated by using this model. Furthermore, changes of flow depth and hydraulic properties, such as width of bottom, flow depth, slope of the channel bottom, and hydraulic radius for 13 cross sections were calculated and the results have been summarized in table 1 . These stages were repeated for return periods of $10,30,50$ and 100 years too.

\section{$2.2[$ HEC-6] computer model}

This model is a one-dimensional movable boundary open channel flow numerical model designed to simulate and predict changes in river profiles resulting from scour and deposition over moderate time periods. [HEC-6] can be 
used to predict the impact of making one or more of those changes on the river hydraulic, sediment transport rates, channel geometry and estimate possible maximum scour during large flood events. Input data are grouped into the categories of geometry, sediment, hydrology, and special commands. Scour or deposition at each cross section can be determined by [HEC-6] model [4]. In this case study erosion or deposition was calculated in 13 cross sections. Results are summarized in table 2 .

Table 1: Amounts of hydraulic parameters for flood event with return period of 25-yr(s) for Koohsefid River.

\begin{tabular}{|c|c|c|c|c|}
\hline $\begin{array}{c}\text { Cross section } \\
\text { number }\end{array}$ & $\begin{array}{c}\text { Wide of } \\
\text { bottom }(\mathrm{m})\end{array}$ & $\begin{array}{c}\text { Flow depth } \\
(\mathrm{m})\end{array}$ & $\begin{array}{c}\text { Slope } \\
(\%)\end{array}$ & $\begin{array}{c}\text { Hydraulic radius } \\
(\mathrm{m})\end{array}$ \\
\hline 1 & 116.29 & .49 & 2.2 & .41 \\
\hline 2 & 86.78 & .56 & 2.2 & .31 \\
\hline 3 & 93.2 & .76 & 2.2 & .54 \\
\hline 4 & 62.15 & .63 & 2.2 & .51 \\
\hline 5 & 72 & .66 & 2.2 & .58 \\
\hline 6 & 82 & .56 & 2.2 & .64 \\
\hline 7 & 143 & .35 & 2.2 & .4 \\
\hline 8 & 100 & .71 & 2.1 & .53 \\
\hline 9 & 153 & .41 & 2.1 & .34 \\
\hline 10 & 167.3 & .32 & 2.3 & .42 \\
\hline 11 & 146.6 & .49 & 2.2 & .32 \\
\hline 12 & 116 & .54 & 2.2 & .22 \\
\hline 13 & 87.4 & .77 & 2.3 & .32 \\
\hline
\end{tabular}

Table 2: $\quad$ Determination of erosion or deposition by [HEC-6] model.

\begin{tabular}{|c|c|c|c|}
\hline $\begin{array}{c}\text { Cross section } \\
\text { number }\end{array}$ & $\begin{array}{c}\text { Length of river } \\
(\mathrm{m})\end{array}$ & Deposition & Erosion \\
\hline 13 & 2500 & Deposition & \\
\hline 12 & 2150 & Deposition & Erosion \\
\hline 11 & 1950 & & Erosion \\
\hline 10 & 1750 & Deposition & \\
\hline 9 & 1550 & & Erosion \\
\hline 8 & 1400 & Deposition & Erosion \\
\hline 7 & 1200 & & Erosion \\
\hline 6 & 1000 & Deposition & Erosion \\
\hline 5 & 800 & & Erosion \\
\hline 4 & 600 & & \\
\hline 3 & 400 & Deposition & \\
\hline 2 & 200 & & \\
\hline 1 & 0 & &
\end{tabular}




\section{Determination the capacity of sediment transport in river}

Sediment transport is calculated by [HEC-6]. The sediment transport functions for bed material in the program are the following: Toffaleti's (1966), Madden's (1963), Yang's (1973). Duboy's, Ackers-White (1973), Colby (1964), Taffaleti (1966) and Schiklitsch (1930) combination, Meyer-Peter and Muller (1948) Toffaleti and Meyer-Peter and Muller combination [4]. All of the functions for sediment transport used for either methods, Interagency Committee on Water Resources (I.C.W.R) and Toffaleti method to determine the fall velocity. The values of sediment loads were computed with different return periods by two method of fall velocity. Measured data by Abbasabad hydrometry station was used to verify the model's results. Equation 1 shows the relationship between suspended load and maximum flood at this station.

$$
\mathrm{Qs}=3.518 \mathrm{Qw}^{2.023}
$$

where Qs = suspended load in (Ton/day); and Qw = maximum flood in $\left(\mathrm{m}^{3} / \mathrm{sec}\right)$. Table 3 and figure 1 present the results analysis.

Table 3: Comparison of measured and [HEC-6] model sediment load (Ton/day).

\begin{tabular}{|c|c|c|}
\hline Return period (year) & $\begin{array}{c}\text { Measured } \\
\text { (Abbasabad station) }\end{array}$ & $\begin{array}{c}\text { Toffaleti's equation } \\
{[\text { HEC-6] }}\end{array}$ \\
\hline 10 & 42480 & 54049 \\
\hline 25 & 57124 & 70575 \\
\hline 30 & 58199.5 & 84668 \\
\hline 50 & 117048 & 26397 \\
\hline 100 & 209448 & 203741 \\
\hline
\end{tabular}

There is a significant relationship between measured values and [HEC-6] model's results as shown in figure 1 .

\section{Conclusions}

This paper investigates previous articles about sedimentation in channels and reservoir damns and introduces two computer models called [HEC-2] and [HEC-6]. [HEC-2] was used to determine water surface profile for flood events that occurred in 1990, 1998, 1999 and for flood events with different return periods including 10, 25, 30, 50 and 100 years too, related to Koohsefid River. [HEC-2] model results were compared with floodmark and attribute satisfactory 
result. [HEC-6] was used to predict values of transport sediment and erosion in river. These results were checked with different transport capacity sediment formulas for such prediction. Between them, Toffaleti's formula using fall velocity introduced by Interagency Committee on Water Resources (I.C.W.R) approach shows the highest correlations with measured values as shown by figure 1. Based on this comparative analysis, it's recommended that [HEC-2] and [HEC-6] are used to management of river engineering.

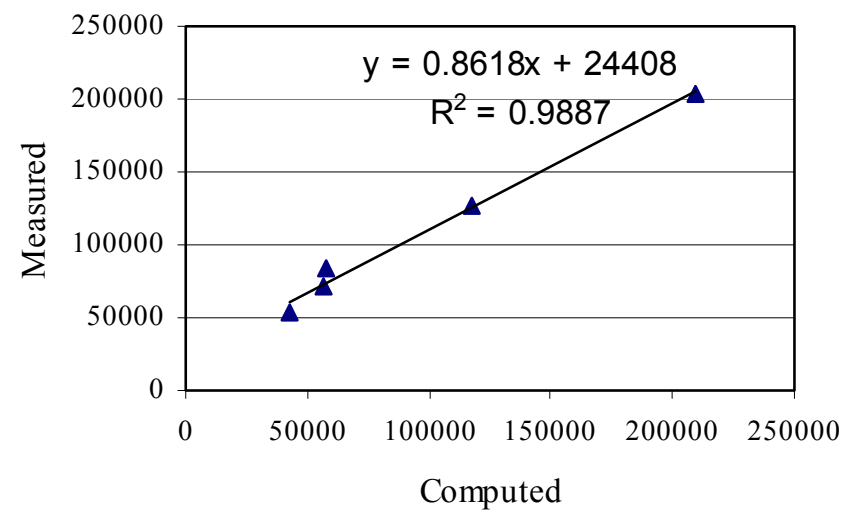

Figure 1: Comparison of values measured by hydrometry station and amount of sediment load calculated by [HEC-6] model (ton/day).

\section{References}

[1] Moein taghavi, M., Comprehensive investigation of doorodzan reservoir water surface profile and sedimentation by [HEC-2] and [HEC-6] models, M. Sc. thesis, Shiraz University, Iran, pp. 250, 1993.

[2] Najarchi, M., Investigation on sedimentation in irrigations and drainage plain using [HEC-6] model, M. Sc. thesis, Shiraz University, Iran, pp.230, 1996.

[3] Monem, M.J., Analysis of sensitivity [HEC-6] medal in alluvial channels, Proc. of the 7th Seminar River Engineering, Chamran Ahvaz University, Iran, pp. 1 12, 1994.

[4] HEC-6, 1993, Scour and deposition rivers and reservoirs. U.S. Army Corps of Engineers, Hydrologic Engineering Center.

[5] HEC-2, 1991, Water surface profile. U.S. Army Corps of Engineers, Hydrologic Engineering Center. 